Revista de Economia Política, vol. 37, no 2 (147), pp. 287-303, abril-junho/2017

\title{
Os novos bancos de desenvolvimento: independência conflitiva ou parcerias estratégicas?
}

\author{
The new development banks: conflicting independence \\ or strategic partnerships?
}

RENATO BAUMANN*

RESUMO: A criação de dois novos bancos de desenvolvimento - o NDB e o AIIB - tem motivado um debate sobre se eles afetarão o funcionamento dos bancos de desenvolvimento existentes e se eles contribuirão para estimular o desenvolvimento econômico em países de baixa renda. Este artigo mostra algumas diferenças entre as duas novas instituições, apresenta algumas estimativas do seu crescimento potencial num futuro próximo e argumenta que é muito provável que os dois bancos - por razões técnicas e financeiras trabalhem em conjunto com os bancos de desenvolvimento existentes, em vez de competir com eles.

PALAVRAS-CHAVE: Bancos de desenvolvimento; infraestrutura; BRICS; AIIB.

ABSTRACT: The creation of two new development banks - the NDB and the AIIB - has motivated a debate as to whether they will affect the working of the existing development banks, and to whether they will contribute do foster economic development in low income countries. This article shows some differences between the two new institutions, present some estimate of their potential growth in the near future and argues that it is very likely that the two banks will - for both technical and financial reasons - work together with the existing development banks, rather than compete with them.

KEYWORDS: Development banks; infrastructure; BRICS; AIIB.

JEL Classification: E22; F21; F43; F53; F55; G24.

\section{INTRODUÇÃO}

O Brasil é sócio fundador do Banco dos BRICS (grupo que reúne Brasil, Rússia, Índia, China e África do Sul). De fato, o acordo formal de sua criação foi fir-

\footnotetext{
* IPEA e UnB. E-mail: renatobauma@gmail.com. Submetido: 17/Fevereiro/2016; Aprovado: 1/Abril/2016. As opiniões aqui são inteiramente pessoais e podem não corresponder às das referidas instituições.
} 
mado pelos Chefes de Estado dos cinco países na reunião de cúpula que teve lugar em Fortaleza, em 2014.

Essa condição naturalmente eleva as expectativas quanto a se conseguir acesso a montantes expressivos de financiamento desse banco, para projetos em território nacional. Isso é verdade tanto para o Brasil quanto para os demais países participantes do grupo dos BRICS.

E há expectativa de que as condicionalidades sejam distintas das cobradas por outros agentes financeiros já em operação.

Essa expectativa pode estar associada a uma visão de que esse banco operará de forma radicalmente distinta e desafiadora com relação a outros bancos de desenvolvimento. No entanto, a probabilidade de que isso venha a ocorrer não parece ser muito grande, como se procurará sugerir aqui.

A Cidade de Monterrey, no México, sediou (18-22 de março de 2002) Conferência que contou com a presença de mais de 50 Chefes de Estado e de Governo e mais de 200 ministros, além de dirigentes do setor privado e da sociedade civil, funcionários de alto nível de todas as principais organizações financeiras, comerciais, econômicas e monetárias intergovernamentais. Nessa oportunidade foram discutidas questões relativas às finanças e ao desenvolvimento.

Essa foi a primeira vez em que ocorreu troca de opiniões entre governos, sociedade civil, empresários e instituições interessadas sobre temas relacionados ao financiamento do desenvolvimento econômico.

Esse esforço deu origem a um documento intitulado Consenso de Monterrey, que resume as principais formas de luta contra a pobreza no mundo, incluindo seis linhas de intervenção prioritárias: a mobilização dos recursos financeiros nacionais a serviço do desenvolvimento; a mobilização dos recursos internacionais a serviço do desenvolvimento; o comércio internacional como motor de crescimento e desenvolvimento; o reforço da cooperação financeira e técnica internacional ao desenvolvimento; o alívio do peso da dívida externa dos países mais pobres e o reforço da coerência entre os sistemas monetários, financeiros e comerciais internacionais de apoio ao desenvolvimento.

A existência desse documento de consenso deu origem a um conjunto de iniciativas de diversos tipos, desde a formação de grupos de estudo e monitoramento das ações que se seguiram a Monterrey, ao estímulo a diversas iniciativas relacionadas com o financiamento de economias menos desenvolvidas, consideradas à luz dos compromissos assumidos naquela oportunidade.

A preocupação com a promoção do desenvolvimento econômico tem motivado um conjunto de iniciativas ao longo do tempo. Já desde pelo menos os anos 1940, com a criação de Comissões Econômicas Regionais das Nações Unidas, essa dimensão tem estado presente. A partir da Cúpula de Bandung, em 1950, a movimentação de países em desenvolvimento tomou novo alento.

No início da década seguinte, a criação da UNCTAD cristalizou institucionalmente a preocupação com a inserção internacional dos países em desenvolvimento. São numerosas as manifestações em favor desses países, por exemplo, no âmbito das negociações comerciais multilaterais. Mais recentemente, sobretudo após a 
crise de 1997, e mais particularmente depois do Consenso de Monterrey, as manifestações de inconformidade com a governança no sistema financeiro global passaram a ser recorrentes.

A consideração da importância de algumas economias em desenvolvimento no cenário global - portanto a necessidade de sua participação de modo mais incisivo na governança - explica, em grande medida, a evolução recente das negociações no âmbito da Organização Mundial do Comércio, a formação do G-20 e a criação dos BRICS, entre outras iniciativas.

Ao mesmo tempo, a relação entre esse propósito de apoiar as economias em desenvolvimento e as condições existentes para financiar os projetos de investimento demandados para tanto levou a iniciativas como a Cúpula de Monterrey e a criação, por exemplo, de grupos de especialistas para propor ajustes na arquitetura financeira internacional.

Um movimento paralelo, de iniciativa individual por parte de alguns países, tem igualmente contribuído para, se não alterar no curto prazo, certamente qualificar o formato tradicional da arquitetura financeira internacional. $\mathrm{O}$ exemplo mais eloquente é a iniciativa chinesa de reconstituição - em novos moldes - da antiga Rota da Seda, através de um conjunto ambicioso de projetos que contribuirão para intensificar os vínculos daquela economia com diversas outras, em termos da movimentação mais fluida de mercadorias, serviços e pessoas.

A avaliação de que existe um excesso de demanda por recursos para investimento em infraestrutura que supera o potencial disponível nas instituições multilaterais existentes, a consideração de que a maior parte dos recursos disponíveis tem sido canalizada para projetos nos países avançados, e a perspectiva de que não haverá em curto prazo aumento de capital nas principais instituições financiadoras levou à criação de novas instituições, como o Banco dos BRICS (também chamado de Novo Banco de Desenvolvimento, e conhecido pela sigla NDB, correspondente à sua designação em inglês) e o Banco Asiático para Investimento em Infraestrutura (AIIB, segundo sua designação em inglês).

Isso traz à consideração o debate não apenas sobre a contribuição desses dois Bancos, como também sua relação com as instituições semelhantes existentes e o ambiente econômico vigente no momento em que ambos começam a operar.

Este trabalho apresenta, na seção a seguir, o cenário atual dos bancos de desenvolvimento, como tela de fundo para se entender o contexto em que as duas instituições foram criadas. A terceira seção mostra as características específicas dos dois novos Bancos. Ela é seguida por uma discussão sobre as relações dos novos Bancos com as instituições semelhantes já em operação. A partir da constatação de que os novos Bancos buscarão atrair recursos de terceiros a quinta seção traz alguns indicadores relativos ao cenário de provável disponibilidade de recursos e à magnitude da demanda por financiamento para projetos de infraestrutura em escala global. A partir dos indicadores apresentados, a sexta seção traz uma tentativa de síntese dos desafios impostos aos novos Bancos e as perspectivas para sua atuação. A sétima seção apresenta algumas considerações de ordem geral. 


\section{O CENÁRIO ATUAL}

O número de bancos de desenvolvimento no mercado internacional tem aumentado de forma significativa. Por exemplo, segundo dados da Moody's ${ }^{1}$, essa empresa faz avaliação de risco de não menos que 35 bancos multilaterais de desenvolvimento. E aí não estão incluídos outros agentes importantes, como o BNDES brasileiro.

De modo geral, trata-se de instituições financeiramente sólidas: nunca houve um caso de quebra, e apenas um episódio de chamada de capital. A maior parte dessas instituições é classificada como de risco baixíssimo (classificações Aaa e Aa, segundo os critérios da Moody's), e seu aumento de capital é basicamente constituído de aportes de recursos públicos. De fato, a crise de 2008-09 mostrou que vários governos lançaram mão da capacidade dessas instituições enquanto ferramenta de política anticíclica, e de fato elevaram seu capital. Como é sabido, esse foi certamente o caso, aqui no Brasil, dos aportes extraordinários de recursos ao BNDES e outros bancos públicos.

Em que pesem esses indicadores, contudo, há três características importantes na atuação dos bancos multilaterais de desenvolvimento.

Primeira, seu peso nos fluxos financeiros globais é muito reduzido: o valor financiado por essas instituições é bem menor que os montantes observados a título de transações interbancárias (empréstimos, cartas de crédito, aceites), investimentos diretos e transações com títulos. A estimativa ${ }^{2}$ é de que existem hoje US\$ 93 trilhões de ativos de investidores institucionais (fundos de pensão, companhias de seguro, fundos de investimento e fundos públicos de reserva de pensões), enquanto o financiamento de projetos de infraestrutura representa transações da ordem de "apenas" US\$ 3 trilhões.

Os bancos de desenvolvimento atualmente proporcionam apenas a décima parte dos recursos para infraestrutura, e seu investimento em infraestrutura vem declinando nas últimas décadas ${ }^{3}$, a exemplo do Banco Mundial, que em 2013 destinou menos de $1 / 3$ dos empréstimos a projetos de infraestrutura.

Esses projetos básicos têm não apenas contado com menos recursos, como têm encontrado barreiras importantes nas restrições fiscais de diversos países. A alternativa de financiamento privado, por sua vez, demanda apoio financeiro através de garantias, participação em capital ou empréstimos sindicados, o que demanda um grau maior de sofisticação financeira ${ }^{4}$.

Segunda, uma parcela importante das transações por parte dos bancos multilaterais de desenvolvimento é realizada com economias avançadas. Segundo dados

\footnotetext{
${ }^{1}$ Hess (2015).

${ }^{2}$ Idem.

${ }^{3}$ Humphrey (2015).

${ }^{4}$ Idem.
} 
apresentados por Hess (2015) as transações desses bancos com países de alta renda superam os US\$ 600 bilhões, enquanto as transações com países de renda média não atingem nem metade desse valor, e com os países de renda baixa os montantes ficam muito aquém dos US\$ 100 bilhões. A ironia dessa situação é que para os países de renda alta os compromissos com os bancos multilaterais de desenvolvimento tem um peso reduzido (em torno de $4 \%$ do seu PIB conjunto), enquanto para os países mais pobres o pouco que é recebido corresponde à décima parte do seu produto nacional.

A terceira característica relevante é que os bancos multilaterais de desenvolvimento tendem a ter atuação de forma especializada, em setores e em regiões específicas. Alguns exemplos são o NADB (North American Development Bank), focado em projetos ambientais na fronteira entre os Estados Unidos e o México, o Shelter Afrique, concentrado no setor habitacional na África, e o Apicorp (Arab Petroleum Investments Corporation), para o setor de energia nos países do Golfo Pérsico.

Nesse ambiente, e tendo em vista que não se espera que venha a ocorrer em curto prazo aumento de capital dos maiores bancos multilaterais de desenvolvimento, como o BID e o Banco Mundial, que têm atuação mais ampla, tanto em termos setoriais quanto geográficos, não surpreende que exista demanda por novas instituições, que contribuam para viabilizar o financiamento de projetos de infraestrutura nas economias menos desenvolvidas.

As estimativas ${ }^{5}$ são de que a necessidade de recursos por parte das economias em desenvolvimento para financiar os projetos necessários em infraestrutura são da ordem de US\$ 2 trilhões anuais. As instituições multilaterais existentes têm capacidade para proporcionar US\$ 1 trilhão anual para esse propósito. Isso significa que existe um excesso de demanda da ordem de US\$ 1 trilhão anual, apenas para investimento em projetos de infraestrutura, e apenas por parte dos países em desenvolvimento.

Essa é, em grande medida (associada ao propósito de contar com processos mais expeditos de projetos e condicionalidades consideradas mais apropriadas por parte dos emprestadores), a motivação que levou os países-membros dos BRICS a criarem o Novo Banco de Desenvolvimento (NDB).

Esse banco foi originalmente proposto pela Índia, quando da reunião de cúpula dos BRICS de 2012, que teve lugar em Nova Delhi. No ano seguinte, na cúpula de Durban, na África do Sul, a criação do banco foi formalmente aprovada, e em meados de 2014, em Fortaleza, os cinco países assinaram o acordo formal de criação da instituição. O sucesso da operação desse banco influenciará, em grande medida, as percepções com relação a todo o exercício de consolidação do grupo dos BRICS.

Ao mesmo tempo, em outubro de 2013, o Presidente Xi Jiping e o Premiê Li Keqiang, da China, visitaram diversos países do Sudeste da Ásia para anunciar a criação do AIIB. Essa instituição foi concebida como parte de um conjunto de

\footnotetext{
${ }^{5}$ Segundo Wang (2015) e Griffith-Jones (2014).
} 
iniciativas chinesas mais ambiciosas, chamadas de "Cinturão Econômico da Rota da Seda" e "Rota Marítima da Seda no Século XXI", que formam a chamada iniciativa "Um Cinturão, Uma Estrada" (mais conhecida por seu nome em inglês, 'One Belt, One Road'). Trata-se de um conjunto de projetos no valor total de US\$1,4 trilhões, com o objetivo de estreitar os laços econômicos da China com outros países asiáticos e ocidentais, revivendo em novos moldes as atividades da antiga Rota da Seda, de enorme importância nos acontecimentos universais no século XVI, ao facilitar a movimentação de mercadorias, serviços e pessoas entre os países afetados.

Se atualizados a preços de hoje os valores empregados no chamado Plano Marshall, que viabilizou a recuperação das economias europeias após a Segunda Guerra Mundial, a iniciativa de criação do AIIB corresponderia a 12 vezes o Plano Marshall. Isso dá uma ideia do grau de ambição envolvido, e do potencial impacto geopolítico.

A criação do AIIB contou com a assinatura de 50 membros fundadores, países das mais diversas regiões, inclusive o Brasil, em setembro de 2015.

A criação dessas duas novas instituições tem motivado diversas reações, seja de ceticismo com relação ao seu desempenho, em vista do tamanho comparativamente reduzido de seu capital em comparação com outras instituições, seja de preocupação quanto a se constituírem em alicerces de uma nova ordem econômico-política internacional, entre outras. A próxima seção apresenta as principais características de ambas.

\section{OS DOIS NOVOS BANCOS}

O NDB iniciou suas operações com um capital subscrito de US\$ 50 bilhões, igualmente distribuídos entre os cinco países BRICS ${ }^{6}$, e um capital inicial autorizado de US\$ 100 bilhões. O poder de voto de cada país-membro é igual à sua participação no estoque de capital do banco. A participação no capital do banco é aberta aos demais países-membros das Nações Unidas. A cada intervalo de não mais de cinco anos haverá revisão do montante de capital do Banco.

O NDB tem um Conselho de Governadores, uma Diretoria, um Presidente e Vice-Presidentes. O Presidente é proveniente de um dos cinco países BRICS, de forma rotativa, e há pelo menos um Vice-Presidente para cada um dos demais BRICS. As decisões são tomadas por maioria simples. Sua sede é em Shangai e há um escritório regional em Johannesburgo.

As funções designadas para o Banco compreendem:

I. Financiar projetos sustentáveis de infraestrutura, públicos ou privados, nos países BRICS e outras economias emergentes e em países em desenvolvi-

\footnotetext{
${ }^{6}$ Sendo US\$ 10 bilhões de capital integralizado e US\$ 40 bilhões de 'chamada de capital'.
} 
mento, através da provisão de empréstimos, garantias, participação no capital e outros instrumentos financeiros;

II. Cooperar com organizações internacionais e entidades nacionais públicas ou privadas, sobretudo instituições financeiras internacionais e bancos de desenvolvimento nacionais;

III. Proporcionar assistência técnica para a preparação e implementação de projetos sustentáveis de infraestrutura a serem apoiados pelo NDB;

IV. Apoiar projetos sustentáveis de infraestrutura envolvendo mais de um país;

V. Estabelecer Fundos Especiais para atender a seus propósitos.

O NDB poderá proporcionar financiamento em moeda local do país em que a operação ocorrerá, adotando medidas adequadas para evitar desencontros expressivos entre paridades.

O AIIB é um pouco distinto, a começar pelo seu foco limitado a projetos na Ásia. Também o critério de seleção para os países participantes é diferente. No caso do NDB essa participação está aberta aos membros das Nações Unidas; já no caso do AIIB, a participação no Banco é para os países-membros do Banco Mundial e do Banco de Desenvolvimento da Ásia.

Os objetivos explícitos do Banco são: i) promover o desenvolvimento econômico sustentável, criar riqueza e melhorar a infraestrutura na Ásia e ii) promover a cooperação regional e complementaridade no trato dos desafios do desenvolvimento, operando em cooperação estreita com outras instituições bilaterais e multilaterais.

O foco de atuação do AIIB é o desenvolvimento de infraestrutura e setores produtivos, nas áreas de energia, transporte e telecomunicações, infraestrutura rural, desenvolvimento agrícola, abastecimento de água, saneamento, proteção ambiental, desenvolvimento urbano e logístico, entre outros.

No final de junho de 2015 representantes de 57 países participaram de cerimônia em Pequim, na qual 50 deles $^{7}$ assinaram o documento com os Artigos do Acordo para criação do AIIB. A possibilidade de assinaturas posteriores foi ampliada até o dia 31 de dezembro daquele ano.

O Banco tem sede em Pequim e durante seu processo de implementação foi criado um Secretariado Provisório. Toda comunicação externa é feita exclusivamente por parte do Ministério das Finanças da China.

O capital inicial do AIIB é de US\$ 100 bilhões, sendo US\$ 20 bilhões integralizados e os restantes US\$ 80 bilhões de "chamada de capital"

\footnotetext{
${ }^{7}$ Austrália, Áustria, Azerbaijão, Bangladesh, Brasil, Brunei, Camboja, China, Egito, Finlândia, França, Geórgia, Alemanha, Islândia, Índia, Indonésia, Irã, Israel, Itália, Jordânia, Cazaquistão, Coreia do Sul, Quirguistão, Laos, Luxemburgo, Maldivas, Malta, Mongólia, Mianmar, Nepal, Holanda, Nova Zelândia, Noruega, Omã, Paquistão, Portugal, Qatar, Rússia, Arábia Saudita, Cingapura, Espanha, Sri Lanka, Suécia, Suíça, Tajiquistão, Turquia, Emirados Árabes Unidos, Reino Unido, Uzbequistão e Vietnã.
} 
O capital do Banco pode ser ampliado, se aprovado por 2/3 dos votos dos Governadores que representem não menos de 3/4 dos membros com poder de voto. Isso é chamado, no acordo de criação do Banco, de "SuperMaioria".

Outra diferença entre o NDB e o AIIB é que este último enfatiza a participação de países diversos. Por exemplo, no acordo de criação do AIIB é incluída condição diferenciada para atrair a adesão de países menos desenvolvidos. Caso uma economia com menor capacidade queira aderir ao capital do Banco ela terá possibilidade de pagar sua inscrição em dólares ou outra moeda conversível em até dez parcelas (cada uma correspondendo a 1/10 do valor total), e até metade do valor devido em sua moeda nacional.

O AIIB tem um Conselho de Governadores, um Conselho de Diretores, um Presidente e um ou mais Vice-Presidentes.

O Conselho de Governadores é composto por representantes dos países-membros. A presidência desse Conselho mudará a cada ano, por eleição entre os participantes. O Conselho de Diretores é composto de doze membros, sendo nove dos quais da região asiática. Os Diretores não podem ser membros do Conselho de Governadores. O mandato dos Diretores é de dois anos, podendo ser reeleitos. Esse Conselho, por sua vez, elege o Presidente do Banco para um período de cinco anos, sendo permitida uma reeleição.

As funções designadas do AIIB compreendem:

i. Financiar, cofinanciar ou participar em empréstimos diretos;

ii. Participar no capital de instituições ou empresas;

iii. Prover garantia, total ou parcial, de empréstimos para desenvolvimento econômico;

iv. Utilizar recursos de Fundos Especiais;

v. Prover outros tipos de financiamento, desde que aprovados pelos governadores

A adição de dois novos bancos de desenvolvimento a um ambiente já povoado por dezenas de outros bancos de desenvolvimento, com mandatos de níveis nacional, regional e multilateral, traz à consideração as questões associadas à provável relação entre os novos bancos e os bancos já em operação.

\section{OS NOVOS BANCOS E AS INSTITUIÇÕES EXISTENTES}

À época do anúncio de criação dos dois novos bancos, sobretudo o NDB, que veio à luz um pouco antes, houve diversas críticas e manifestações de ceticismo. Alguns analistas chegaram mesmo a questionar o fato de algumas economias emer-

\footnotetext{
${ }^{8}$ Diferente do que é considerado "Maioria Especial": maioria dos votos dos Governadores que representem a maioria dos membros com poder de voto.
} 
gentes serem receptoras de programas de assistência financeira não concessional (isto é, empréstimos, investimentos e garantia de empréstimos) de parte dos bancos multilaterais de desenvolvimento, uma vez que dispõem de recursos suficientes para capitalizar um novo banco de desenvolvimento?.

No caso específico do NDB, parte do ceticismo está associada a um questionamento mais amplo, com relação à própria iniciativa dos BRICS. Como são países com histórias, culturas, instituições e objetivos em geral distintos, diversos analistas discutem, desde a primeira reunião de cúpula, em 2010, a razão de ser desse exercício. Em alguns casos os BRICS são vistos como essencialmente um movimento que acabará envolvendo o Brasil e a África do Sul nos conflitos de longa data da Eurásia.

O voto de abstenção dos quatro outros BRICS na Assembleia Geral da ONU, quando foi condenado o conflito entre a Rússia e a Ucrânia, é um exemplo de que poderá haver no futuro próximo demanda para um alinhamento mais nítido de solidariedade entre os membros do grupo quando um deles estiver envolvido em conflitos com terceiros países.

Nesse contexto o NDB, por ser uma iniciativa de âmbito multilateral, mas não regional, constitui um desafio único: como consolidar uma instituição financeira não-regional. A experiência anterior, na Conferência de Bretton Woods, teve lugar em contexto totalmente distinto e com participação das principais economias do planeta. O sucesso ou não nas operações do NDB certamente influenciará a percepção externa com relação às perspectivas do grupo dos BRICS.

A criação do NDB foi vista por alguns analistas como um movimento de contestação à governança global existente. Os países BRICS têm reiteradamente se empenhado em aumentar sua influência sobre os processos decisórios do Banco Mundial e do FMI, entre outras instâncias. Sua movimentação nesse sentido, no âmbito do G-20, assim como as repetidas menções ao desagrado por não verem concretizada a mudança aprovada nas cotas do Fundo, são indicações claras nesse sentido.

Ao mesmo tempo, contudo, esses países têm se empenhado em explicitar seu interesse no bom relacionamento com as instituições multilaterais existentes, como demonstrado pela inclusão formal, nos acordos de constituição de ambos os novos Bancos, do propósito de operar de modo cooperativo com essas instituições. Uma forma de eliminar ou ao menos reduzir os temores quanto a uma eventual postura contestatória, de parte dos BRICS.

Outra crítica está relacionada com a reduzida dimensão dos dois novos Bancos, em termos do valor do capital inicial autorizado. Se os bancos multilaterais de desenvolvimento são, em geral, de dimensões limitadas em relação ao volume de recursos disponível, como indicado acima, os dois novos Bancos, ambos com capital inicial de US\$ 100 bilhões, são relativamente minúsculos. Para fins de compa-

\footnotetext{
${ }^{9}$ Nelson (2015).
} 
ração, apenas o maior banco multilateral de desenvolvimento, o Banco Europeu de Desenvolvimento, possui ativos da ordem de US\$ 600 bilhões.

Isso não que dizer, contudo, que essas proporções se mantenham inalteradas.

Griffith-Jones (2014) sugere o seguinte exercício, como forma de avaliar a contribuição do NDB.

Supondo um estoque de capital de US\$ 100 bilhões, dos quais $20 \%$ integralizados, o nível de empréstimos anuais, em 20 anos, poderia alcançar o montante de US\$ 350 bilhões, ou aproximadamente US\$ 34 bilhões por ano. Isso permitiria financiar projetos em valor de pelo menos US\$ 68 bilhões anualmente, dado que haveria cofinanciamento com outras fontes de recursos.

Existe, no entanto, um elemento multiplicador, dada a razão entre o valor dos empréstimos e o estoque de capital de um banco. Essa razão, no caso da CAF (Banco de Desarrollo de América Latina), é igual a 2.4.

Assim, supondo um capital integralizado de US\$ 10 bilhões no primeiro ano (como estabelecido no acordo de criação do NDB), estariam disponíveis para empréstimos US\$ 24 bilhões, o que representaria, em dez anos, algo como US\$ 2,4 bilhões anuais.

Mas se considerarmos um retorno de $5 \%$ sobre os empréstimos, os lucros acumulados atingiriam US $\$ 0,12$ bilhão no primeiro ano. Caso esses recursos sejam acrescentados totalmente ao capital para empréstimos, e repetindo esse movimento por vinte anos, o estoque total para empréstimos alcançaria US\$ 86 bilhões, aumentando em US\$ 9 bilhões o valor disponível para empréstimos a cada ano.

Supondo, alternativamente, que o NDB adote política mais agressiva e mantenha uma razão empréstimos/capital igual a 4.8 , em vinte anos o estoque total para empréstimos atingiria US\$ 172 bilhões, com uma disponibilidade para empréstimos a cada ano de quase US\$ 18 bilhões.

Claro, esses números poderiam ser ainda mais expressivos no caso de o NDB conseguir melhorar sua avaliação de risco e captar recursos adicionais.

Se por essa via o NDB conseguisse dobrar seu capital integralizado e se mantivesse a razão empréstimos/capital correspondente ao dobro do praticado pela CAF, em vinte anos o NDB atingiria um volume de empréstimos da ordem de US\$ 350 bilhões, o que o tornaria comparável ao Banco Europeu de Investimento em 2012, quando emprestou um total de US\$ 60 bilhões, dos quais US\$ 32 bilhões para infraestrutura.

$\mathrm{O}$ argumento otimista quanto a um crescimento mais pronunciado do NDB no início está relacionado com o fato de que ele pode se beneficiar da experiência acumulada tanto dos bancos nacionais quanto dos bancos multilaterais de desenvolvimento, e com isso apresentar graus elevados de eficiência já desde os primeiros anos.

Humphrey (2015) apresenta uma visão comparativa dos dois novos Bancos um pouco mais crítica em relação ao NDB.

Primeiro, pelo fato de que no caso do NDB o capital inicial é repartido e limitado aos cinco países BRICS, em proporções iguais. Isso é visto como uma condição básica para preservar o equilíbrio entre desiguais, mas do ponto de vista do mer- 
cado financeiro essa decisão restringe a possibilidade de que uma economia como a chinesa possa fazer aportes mais substantivos, e se veja limitada ao potencial de contribuição por parte da economia menor, a sul-africana.

Segundo, os BRICS preservaram a maior parte do poder decisório nas operações do NDB: um país que não pertença aos BRICS não poderá deter individualmente mais de $7 \%$ dos votos totais. Uma vez mais, se desde a perspectiva política isso assegura a "propriedade" e controle sobre a governança da instituição, ao mesmo tempo pode representar um desestímulo a que novos participantes potenciais se empenhem em aportar recursos adicionais.

Esse conjunto de características pode eventualmente vir a comprometer a classificação de risco do NDB, se o mercado interpretá-las como limitantes à atuação do Banco. E esse é um processo cumulativo: desconfiança de que o NDB não será capaz de captar recursos a custos competitivos com aqueles pagos por outras instituições multilaterais afasta potenciais investidores, o que compromete a perspectiva de crescimento do Banco etc.

Esse não é um problema menor. A grande vantagem comparativa de um banco de desenvolvimento é o fato de que ele conta com recursos públicos e garantia de parte de governos, portanto seu risco é relativamente baixo. Isso permite captar recursos no mercado a custo mais reduzido do que outras instituições e emprestar a custos mais baixos. Mas para tanto é fundamental contar com a confiança dos investidores potenciais, para poder atrair seu interesse em aportar recursos ao Banco.

O caso do AIIB é um pouco distinto. A China reteve a Sede e a Presidência inicial, assim como aportou um volume significativo de recursos, mas abriu mão do monopólio decisório: como indicado acima, os representantes dos mais de 50 países signatários do acordo inicial participarão do processo de constituição do Banco.

Terceiro, no caso do NDB o montante de capital integralizado, de US\$ 10 bilhões, será complementado por US\$ 40 bilhões de 'chamada de capital'. Segundo Humphrey (2015), os bancos multilaterais de desenvolvimento têm usado cada vez menos o recurso a esse tipo de capital, preferindo destacar a razão empréstimos/ capital ou mesmo trabalhando com modelos financeiros mais sofisticados. No caso do NDB os US\$ 10 bilhões são o único capital disponível para empréstimos iniciais. Já no AIIB a China aportou US\$ 10 bilhões, mas atraiu mais de 50 outros países, com o que se estima que o capital inicial para empréstimos pode praticamente dobrar.

Os US\$ 10 bilhões de capital inicial para empréstimos será integralizado - segundo o acordo de criação do NDB - em sete anos. Supondo esse mesmo prazo para ambos os Bancos, e admitindo ademais uma razão capital/empréstimos de $25 \%$, em dez anos, isto é, em 2025, o NDB teria um volume de capital para empréstimos de US\$25-30 bilhões nos primeiros cinco anos e de US\$ 45-65 bilhões nos cinco anos seguintes.

No caso do AIIB, supondo os mesmos sete anos de integralização do capital, e admitindo que a presença diferenciada da China possa influenciar positivamente 
a classificação de risco, Humphrey (2015) sugere que a disponibilidade de capital para empréstimo poderia chegar a cerca de US\$ 70-90 bilhões em dez anos, com potencial de atingir até US\$ 120 bilhões. Considera que no caso do AIIB é maior a possibilidade de operar com uma razão capital/empréstimo mais alta, uma vez mais pela presença da China.

Em ambos os casos os dois Bancos se destacariam entre os bancos regionais de desenvolvimento. O AIIB poderia inclusive atingir dimensão comparável ao BID, mas ambos permaneceriam bem menores que o Banco Mundial.

Os dois Bancos podem se programar para captar recursos não apenas no mercado de capitais, mas também junto a fundos soberanos e aos bancos centrais dos países fundadores. Outras fontes compreendem associações com agências de cooperação, com bancos nacionais de desenvolvimento, uso de mecanismos de cofinanciamento com outras agências ou governos nacionais, entre outras.

Uma vantagem provável de parte dos dois Bancos em relação aos demais bancos de desenvolvimento é não apenas que eles podem se beneficiar da experiência das instituições existentes, como já referido acima, mas também que em ambos os casos os documentos de criação são enfáticos em priorizar baixos custos administrativos, estruturas pequenas e com menores custos.

Não é claro, desde já, exatamente onde se delimitarão os projetos classificados como infraestrutura. Transporte, energia e comunicações são condições claras, mas é possível argumentar que os financiamentos de saúde básica e de mecanismos de absorção de tecnologia também constituem infraestrutura. Ou seja, não é claro o que exatamente se concebe como infraestrutura. A prática dirá. Soma-se a isso o fato de que existem diversas limitações na própria disponibilidade de informação concreta sobre as reais necessidades de investimento de longo prazo, como discutido em OECD (2015).

Seja como for, e dado que ambos os Bancos pretendem operar com números reduzidos de quadros técnicos, haverá um "trade-off” entre contar com uma estrutura administrativa pequena, de baixo custo, mas ao mesmo tempo demandar competência para analisar os projetos complexos de infraestrutura. É provável que essa dupla condição leve naturalmente à intensificação dos mecanismos de cooperação institucional dos dois novos Bancos com as instituições multilaterais existentes, com experiência acumulada em diversas áreas.

E a probabilidade dessa interação é tanto menos estranha porque - ao menos no caso do NDB - foi preservado processo decisório semelhante em grande medida ao observado nas instituições existentes. Deveria, portanto, em princípio, haver alguma facilidade para a cooperação institucional.

De todos os modos, a possível atuação cooperativa entre os novos Bancos e os bancos existentes estará sobredeterminada pelas condições de demanda por projetos a serem financiados por essas instituições e a disponibilidade de recursos ao nível global para viabilizar esses financiamentos. Esse é o tema da próxima seção. 


\section{O CENÁRIO GLOBAL}

No auge da crise de 2008 ficou clara para as autoridades nas principais economias a necessidade de incorporar algumas economias emergentes nas discussões centrais, então centradas no chamado "G-8". A partir de 2009 o grupo foi ampliado para 20 países, com a inclusão de vários emergentes, selecionados segundo critério "ad hoc", e a partir do reconhecimento de que boa parte do dinamismo da economia mundial se devia ao desempenho dessas economias.

A leitura desses indicadores motivou, de parte dos emergentes, um conjunto de iniciativas direcionadas a aumentar sua participação no processo de governança global. Não por outro motivo a primeira aproximação entre autoridades de quatro emergentes teve lugar na segunda metade de 2008, e já em 2009 foi realizada a primeira reunião de cúpula dos então quatro BRICs, com o objetivo explícito de atuar de forma coordenada para tentar ampliar a relevância de sua participação no cenário mundial.

Com o crescimento do produto em alguns desses países superando os dois dígitos anuais, e em outros estando próximo dos $10 \%$, e dada a magnitude dessas economias, parecia inevitável projetar que em pouco tempo haveria uma alteração significativa nas relações de poder econômico, em comparação com o ambiente conhecido das últimas décadas.

A realidade mostrou-se, contudo, mais uma vez mais dura do que se podia prever. A crise se mostrou mais longeva e profunda do que se imaginava. Sua extensão geográfica, afetando um número de países muito além do originalmente previsto, ampliou seus efeitos. Ela trouxe, em paralelo, motivação para novos formatos de produção e comercialização, extrapolando o ambiente puramente financeiro. De fato, tem havido estímulo sem precedentes à adoção de novas técnicas produtivas, novas relações em cadeias produtivas e comerciais entre países diversos e uma preocupação também sem precedentes com o uso de tecnologias limpas, o que tem afetado diretamente algumas economias, a exemplo dos produtores de petróleo.

As medidas anticíclicas adotadas pelas principais economias - EUA, Europa Ocidental e Japão - basicamente centradas em políticas monetárias expansivas, injetaram um total de US\$ 5 trilhões no mercado mundial, com alguns efeitos paralelos.

O barateamento do custo do capital, fruto da liquidez excessiva, alimentou políticas fiscais menos rígidas. De fato, é estimado (Dobbs et al. (2015)) que o déficit fiscal combinado de todos os países tenha atingido um total de US\$ 4 trilhões em 2009.

Essa enorme liquidez teve efeito daninho sobre as taxas reais de câmbio de boa parte dos países em desenvolvimento que não impuseram controles sobre o movimento de capitais. A valorização de diversas moedas nacionais, alimentada ademais por um período de aumento expressivo dos preços de "commodities", implicou perda de competitividade de suas exportações e contribuiu para comprometer os saldos comerciais. Certamente uma história conhecida dos brasileiros. 
Em algumas economias importantes, como a japonesa, mesmo o bombeamento de grande oferta monetária não tem sido capaz de promover a recuperação do ritmo de atividade. A recuperação das economias dos EUA e da União Europeia tem se dado em ritmo que suscita frequentes questionamentos sobre sua sustentabilidade, dado o nível baixo dos indicadores de desempenho.

O menor dinamismo das principais economias implicou menor crescimento nas transações comerciais ao nível mundial. Economias com grande dependência do mercado externo foram afetadas pela menor demanda. O conjunto dos BRICS, que se supunha fosse suplantar em poucos anos as principais economias do planeta, passou a apresentar desempenho bem mais modesto, com ao menos duas das cinco economias - brasileira e russa - em situação de crise, com queda no produto nacional.

O início de recuperação da atividade nos EUA e em alguns países da Europa Ocidental, embora bastante aquém do desejado, tem motivado reconsideração da política monetária expansiva dos últimos anos. A elevação das taxas de juros nessas economias, para reduzir a liquidez excessiva, é um processo que aparenta ser pouco reversível, o que significa que o custo do capital passará a ser mais alto que nos últimos vários anos, e que haverá uma tendência a que capitais hoje aplicados em economias emergentes migrem para os títulos soberanos das principais economias, encarecendo adicionalmente os recursos para os emergentes.

Nesse cenário, a relação entre demanda e oferta de recursos para projetos de investimento básico deverá ser alterada. Isso pode ser relevante para o desenho de estratégias para os novos Bancos.

A consultora McKinsey estima (Dobbs et al. (2015)) que até 2030 o planeta demandará investimentos em estradas, construções, redes ferroviárias, telecomunicações, portos e abastecimento de água em montante da ordem de US\$ 57-67 trilhões. São 60\% a mais do que o mundo investiu entre 1994 e 2012. É importante ter em mente que essa estimativa não de refere apenas a projetos em países em desenvolvimento: também nas economias avançadas a infraestrutura não atualizada tem requerido quantidades expressivas de recursos.

Isso significa que a demanda global por recursos para projetos de infraestrutura será certamente maior nas próximas décadas, precisamente quando o custo do capital tenderá a se elevar, em relação ao passado recente.

Dobbs et al. (2015) também chamam a atenção para o fato de que a população mundial está envelhecendo, com o aumento da expectativa de vida e a redução da taxa de natalidade. Isso impõe aos governos a necessidade de maiores gastos em saúde e seguridade social: estima-se que esses gastos aumentarão entre $4 \%$ e $5 \%$ do PIB global até 2030.

As consequências dessa tendência demográfica são, de um lado, reduzir os graus de liberdade na disponibilidade dos recursos públicos, e de outro, reduzir a taxa de poupança agregada, uma vez que indivíduos mais velhos tendem a poupar menos.

Acrescente-se a essas condições o fato de que ao menos duas das principais economias emergentes - a da China e a da Índia - têm estimulado o consumo in- 
terno, o que contribui para reduzir ainda mais a taxa de poupança disponível, tendo em vista o peso de ambas.

Como resultado, no momento mesmo de aumento da demanda por investimentos básicos deverá ocorrer - tudo o mais mantido constante - um encarecimento dos recursos devido à menor oferta: políticas monetárias menos laxas, menor poupança pública e menos poupança privada.

A se confirmar esse cenário, a competição por recursos será mais acirrada.

Esse desencontro entre o dinamismo da demanda por projetos de investimento em infraestrutura e a disponibilidade de recursos a custos baixos certamente está na agenda das autoridades que neste momento se dedicam a desenhar o formato de operação dos dois novos Bancos. Há desafios e oportunidades. Isso é discutido na próxima seção.

\section{DESAFIOS E POSSIBILIDADES PARA OS NOVOS BANCOS}

As seções anteriores mostraram que os novos Bancos partem com uma dotação de recursos relativamente modesta, em comparação com outras instituições financeiras, mas que isso é estrategicamente positivo para conseguir construir credibilidade junto às agências de risco e os potenciais investidores, além de que há possibilidades concretas de conseguir um desempenho significativo em poucos anos.

Boa parte das análises enfatiza essa segunda condição: é fundamental o sucesso na atração de recursos de terceiros.

Como já ressaltado, os bancos de desenvolvimento em geral têm razoável atratividade pelo fato de que são garantidos por um ou mais governos, o que reduz o risco para aplicações de recursos nessas instituições. Essa mesma característica também deveria, em princípio, facilitar o acesso dessas instituições a recursos como os dos fundos de pensão e dos fundos soberanos.

A seção na sequência mostrou que as perspectivas de excesso de demanda por recursos provavelmente induzirão uma disputa pelo acesso às principais fontes de recursos.

Ao mesmo tempo foi mostrado, na seção inicial, que os dois novos Bancos prometem operar em projetos de infraestrutura, que sejam ambientalmente sustentáveis, com equipes reduzidas e alto grau de eficiência.

Temos, portanto, um cenário em que haverá, de parte dessas novas instituições, demanda por "expertise" tanto para a análise dos projetos quanto para a avaliação dos seus impactos gerais. Não basta que cada projeto seja rentável, o que já demanda, por si só, conhecimento técnico para sua análise, dada a complexidade dos investimentos em infraestrutura. É preciso, ademais, que seu retorno social supere o retorno privado no longo prazo, para que se justifique a aplicação de recursos nesses projetos.

Essas novas instituições demandarão também, por tudo o que já foi exposto, recursos financeiros adicionais, para o que competirão com as instituições existentes. Boa parte destas já conta com avaliação de risco altamente favorável, enquan- 
to os novos Bancos ainda precisam ganhar credibilidade. E isso num cenário de menor abundância de recursos.

Essas duas tendências sugerem que existe uma probabilidade não pequena de que as novas instituições procurem operar em cooperação com as instituições existentes de modo a: i) se beneficiar do acesso à experiência e qualidade técnica de análise acumulados ao longo de muitas décadas e ii) aumentar a probabilidade de conseguir captar recursos a custos baixos para a execução de iniciativas conjuntas.

\section{CONSIDERAÇÕES GERAIS}

Dois novos bancos de desenvolvimento foram criados num momento em que a taxa global de investimento é mais baixa do que no passado: segundo Dobbs et al. (2015) a razão investimento/PIB mundial era de $25 \%$ na década de 1970 e de $22 \%$ no final da década passada. Isso talvez justifique por si só a sua criação. No entanto, são duas novas adições a um conjunto já variado de instituições.

Ambas as instituições têm seu foco no financiamento de projetos sustentáveis de infraestrutura.

No caso do NDB, para projetos nos próprios países BRICS, outros emergentes e em países em desenvolvimento. $\mathrm{O}$ acordo de criação não elabora o que é considerado infraestrutura nem quais países poderiam se beneficiar.

No caso do AIIB há um pouco mais de precisão, tanto na área de atuação (Ásia) quanto nos setores a serem priorizados. Mas a listagem de setores compreende a expressão "outros", com o que tampouco ficam estabelecidos de forma precisa os limites do que se entende por infraestrutura.

A definição de infraestrutura pode compreender projetos em saúde, educação, e tecnologia, que extrapolam a lógica dos projetos para viabilizar a movimentação física de mercadorias e pessoas ou melhorar a comunicação entre elas. E ainda é preciso melhorar a identificação das reais necessidades de investimento de longo prazo.

Os países fundadores das duas novas instituições têm interesse natural em poder contar com financiamento de projetos nacionais. No caso do AIIB isso só procede para os sócios asiáticos. No caso do NDB há cinco candidatos naturais imediatos.

O que se procurou sugerir aqui é que não necessariamente o uso dos recursos desses Bancos ocorrerá como alternativa crítica a outras instituições existentes. É provável que se encontrem, com alguma frequência no futuro próximo, exemplos de convivência pacífica e cooperação entre os novos Bancos e instituições semelhantes já em operação. As características institucionais, o modo proposto de operação e a conjuntura internacional parecem indicar que existem benefícios nas atividades complementares. 


\section{REFERÊNCIAS BIBLIOGRÁFICAS}

Dobbs, R, J. Manyika, J. Woetzel (2015), No Ordinary Disruption - The Four Global Forces Behind the Trends, Publica Affairs, New York

Griffith-Jones, S. (2014), A BRICS Development Bank: a dream coming true?, UNCTAD Discussion Papers, UNCTAD/OSG/DP/2014/1, March

Hess, Steven (2015), "Multilateral Banks Playing Growing Role in Funding Global Development", apresentação na Conferência Multilateral Development Banks and Asian Investment: Room for More?, no Peterson Institute for International Economics, Washington, DC, setembro

Humphrey, C. (2015), Development revolution or Bretton Woods revisited? The prospects of the BRICS New Development Bank and the Asian Infrastructure Bank, ODI Working Paper 418, April

Nelson, R. (2015), Multilateral Development Banks: Overview and Issues for Congress, CRS Reports, US Congress, 7-5700, R41170, www.crs.gov, December

OECD (2015), Addressing Data Gaps in Long-Term Investment: an Agenda for Research - OECD Report to G20 Finance Ministers and Central Bank Governors, September

Wang, H. (2015), “The New Multilateral Development Banks: Promises and Potential Problems”, apresentação na Conferência Multilateral Development Banks and Asian Investment: Room for More?, no Peterson Institute for International Economics, Washington, DC, setembro 